\title{
Formulating the spring discharge-function for the recession period by analyzing its recession curve: A case study of the Ranichauri spring (India)
}

\author{
A K VASHISHT* and B BAM \\ College of Agricultural Engineering \& Post Harvest Technology (CAEPHT), \\ Central Agricultural University, Ranipool, Gangtok, Sikkim 737 135, India. \\ ${ }^{*}$ Corresponding author.e-mail: akvashisht74@yahoo.com
}

\begin{abstract}
The Greater Himalayan region is witnessing a changing rainfall pattern from the last few decades. Low-intensity longer-duration rainfall events have now been replaced with intense and shorter-duration events that are further responsible for the reduced recharging of the spring catchments. Consequently, the natural springs are either drying up or becoming seasonal. Prediction of spring water availability during the recession period is the key to its proper management. The spring discharge-rate can be forecasted by studying its behaviour for the past recession periods. Expressing recession curve in mathematical terms requires its quantitative analyses in priori. It was found that the fitting of recession-curve (of the Ranichauri spring under study) with two exponential components gives accurate results. The maximum value of exponential coefficient (i.e., 0.0206) represents the major contribution to drainage from the spring-catchment's portion with highest permeability, whereas the minimum value (i.e., 0.0016) represents the major contribution to spring discharge from the portion with lowest permeability. Analyses show that the permeability of the porous medium is responsible for discharge rate and its capacity is responsible for perennial or seasonal behaviour of the spring. Using the mean values of the recession parameters, the master discharge-function of the spring for the recession period is formulated for calculating its discharge-rate during the recession period of any year. Apart from the year 2001, its predictions are in close agreement with the actually monitored data. The efficiency of the formulated master discharge function of the spring for the recession period has been evaluated equal to 0.965 using the Nash-Sutcliffe efficiency criterion.
\end{abstract}

\section{Introduction}

In recent years, the occurrences of extreme events such as droughts and floods have been on rise almost worldwide (Xu et al. 2004). Now it is a proven fact that the climate change is responsible for these hydrological extremes and due to this, availability of freshwater in Asia is projected to decrease as pointed out by the Fourth Assessment Report of the Intergovernmental Panel on Climate
Change (IPCC 2007). The Great Himalayas are also known as Water Tower of Asia (Qiu 2008; $\mathrm{Xu}$ 2008). Marked variation in the elevation along with the vegetation creates highly heterogeneous geography in the Himalayan terrain, and because of that this region has great climatic variability (Xu et al. 2009). Based on regional studies, it has already been pointed out that the climate impacts are already occurring in the Greater Himalayas (Beniston 2003; Cruz et al. 2007). The climatic

Keywords. Spring hydrograph; exponential fitting; gravity spring; recession period; recession curve. 
variability in the region has also changed the rainfall pattern and the predictions show that there will be slight increase in rainfall along with greater intensity (Rees and Collins 2006; Singh et al. 2008; Tambe et al. 2011; Agarwal et al. 2012). This changed pattern is further responsible for the reduced recharging of the spring catchments, whose impact is visible through the diminishing and/or drying-up of the springs during the recession period of the year. Being completely dependent on these springs, the long term sustainability of human population in the region is questionable now.

The only feasible answer to this water scarcity problem in recession period is to store it when it is in excess during monsoon and post-monsoon seasons. However, the construction/purchase of water storage tank without optimizing its size requirement may be highly uneconomical. Depending on the knowledge regarding the future water availability from the spring, the difference in demand and availability can be evaluated. This difference will ultimately decide the dimensions of the tank required for storing the water. Hence, the solution to the said problem solely depends on the prediction of spring's discharge-rate in the recession period.

The graphical representation of temporal discharge variation of a spring is known as spring hydrograph. The behaviour of a spring can be administrated and forecasted by studying and analyzing it. Discharge-rate of a spring does not remain constant. Fluctuation in spring dischargerate can be attributed to the temporal variations in the rate-of-recharge and the prevailing hydrologic and geologic conditions. After attaining a peak (during monsoon or post-monsoon), spring's temporal discharge starts decreasing in general (with minor ups and downs) till the next monsoon. Intermittent rainfall showers due to western disturbances do not affect the spring hydrograph majorly. The part of the spring hydrograph curve that extends from a base to the discharge peak is known as accession curve, whereas the part from discharge peak to the base of the next rise is known as recession curve (figure 1). Rise of accession curve is generally not smooth due to intermittent increase in discharge-rate of the spring. This increase in discharge-rate on irregular basis can be attributed to the irregular increase in head due to intermittent recharging from non-uniform rainfall events. Conversely, drop in recession curve is comparatively uniform (due to lack of any spring catchment recharging) and therefore, is generally opted for study. The study of recession curves is further useful for rainfall/runoff mathematical models, graphical separation of different flow components, estimation of discharge statistics, and indexing the storage capacity of catchment areas

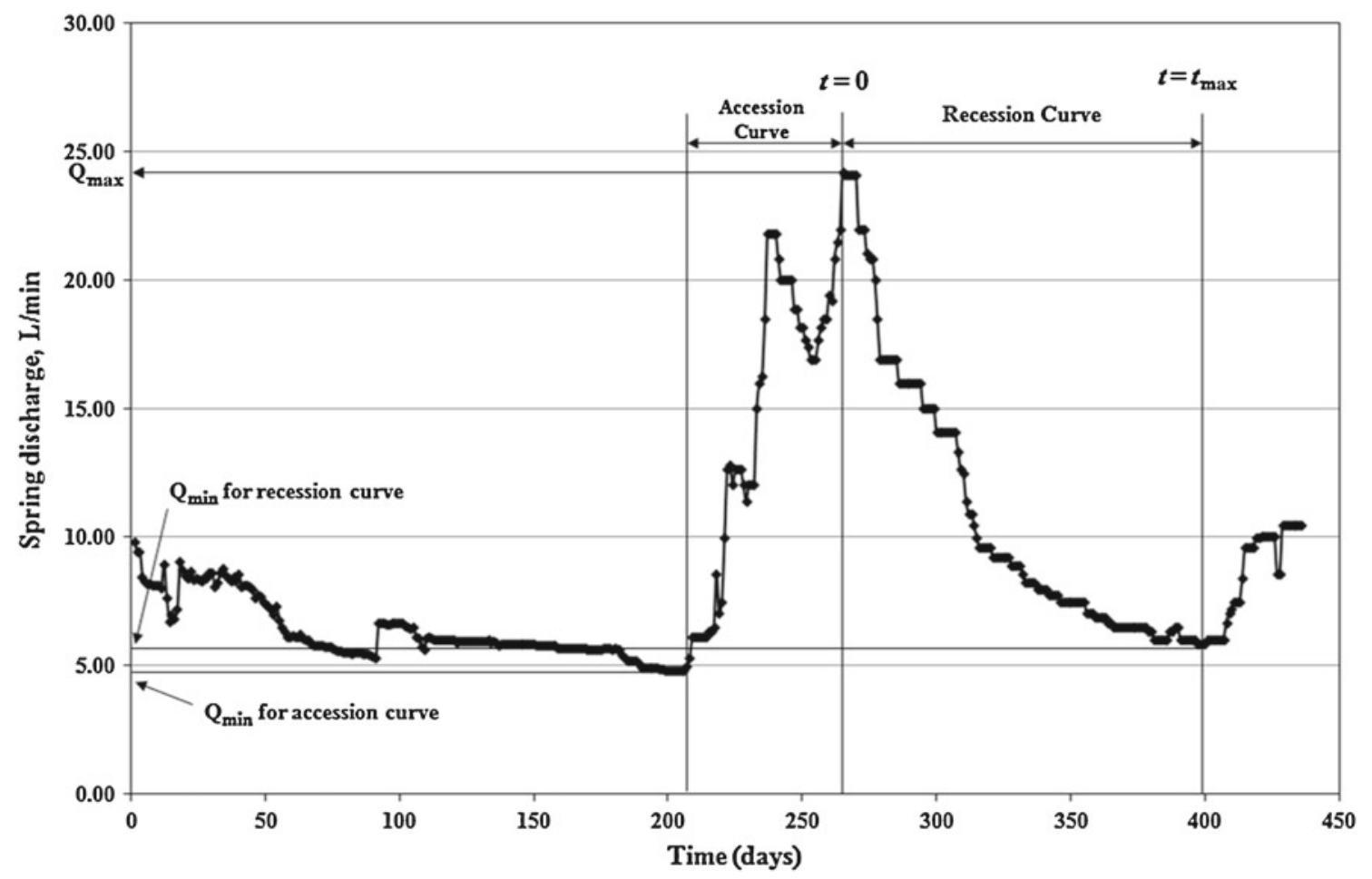

Figure 1. A typical hydrograph of Ranichauri spring. Accession and recession periods are also marked in the figure. 
(Tallaksen 1995). Keeping the above-mentioned discussion in mind, the present study is undertaken with the following objectives:

- To study the recession curves for eight years temporal discharge data of a gravity-spring and delineate its quick- and base-flow values.

- To formulate the spring discharge-function for predicting its discharge-rate in the recession period.

\section{Description of the study area}

Garhwal, in the Western Himalayan region, is drained almost entirely by the Ganga and its tributaries. In comparison to valley areas (near to perennial streams) of the region, the population residing on high reaches face acute water scarcity in summer months. Agarwal et al. (2012) after studying the hydrological behaviour of springs in Chandrabhaga and Danda watersheds of the region, reported that the drying up of springs in early summer can be attributed to the decreased water-retaining capacity of soils which is being degraded by deforestation and thinning of forest cover and/or by a rainfall pattern of increasing high intensity storms and longer dry spells.

The spring selected for the present study is located at the College of Forestry and Hill Agriculture (Uttarakhand University of Horticulture and Forestry), Ranichauri at $30^{\circ} 18^{\prime} 47.09^{\prime \prime} \mathrm{N}$ latitude and $078^{\circ} 24^{\prime} 33.34^{\prime \prime} \mathrm{E}$ longitude at an elevation of $1871 \mathrm{~m}$ above mean sea level, in TehriGarhwal District, Uttarakhand, India. Location of the spring is shown in figure 2. The spring is categorized as gravity spring. Rainfall is monitored from the rain gauge situated in the college itself at location $30^{\circ} 18^{\prime} 44.94^{\prime \prime} \mathrm{N}$ and $078^{\circ} 24^{\prime} 36.72^{\prime \prime} \mathrm{E}$ and at an elevation of $1850 \mathrm{~m}$. It measures the rainfall on a daily basis. The temperature of the region ranges between $3^{\circ}$ and $28^{\circ} \mathrm{C}$. The annual rainfall varies from $1200-1400 \mathrm{~mm}$, of which $70-80 \%$ is normally received during the months from June-September (i.e., monsoon season). The region belongs to the Krol formation and is having phyllite lithology. The soils of the spring catchment are formed under cool and moist climate from rocks of biotite schist and phyllitic material. These are shallow, gravelly, and impregnated with weathered fragments of stones and parent rock. The soils are brown to greyish-brown and dark grey in colour, besides being generally non-calcareous and neutral to slightly-acidic in reaction. The vegetation of the area is dominated with oak and minor shrubs like Myrsine Africana, Berberis lyceum, Rubus ellipticus and Sarcococca hookeriana.

\section{Development of spring hydrographs}

Spring hydrograph represents the temporal variation of its discharge-rate $(Q)$. For the present study, rainfall data as well as daily discharge-rate of the spring monitored for eight years is procured from the All India Co-ordinated Research Project (AICRP) on Groundwater Utilization, Department of Irrigation and Drainage Engineering, G B Pant University of Agriculture and Technology, Pantnagar, Uttarakhand, India. Figure 1 shows that the recession curve generally extends from the month of September/October to April/May next year. Small-scale frequent variations in spring discharge during recession period can be visualized from figure 1 . To reduce the sensitivity of these frequent variations, it was decided to plot the spring discharge-rate on the logarithmic scale. The logarithmic transformation of the discharge-rate creates smoothness in the hydrograph. Keeping this in

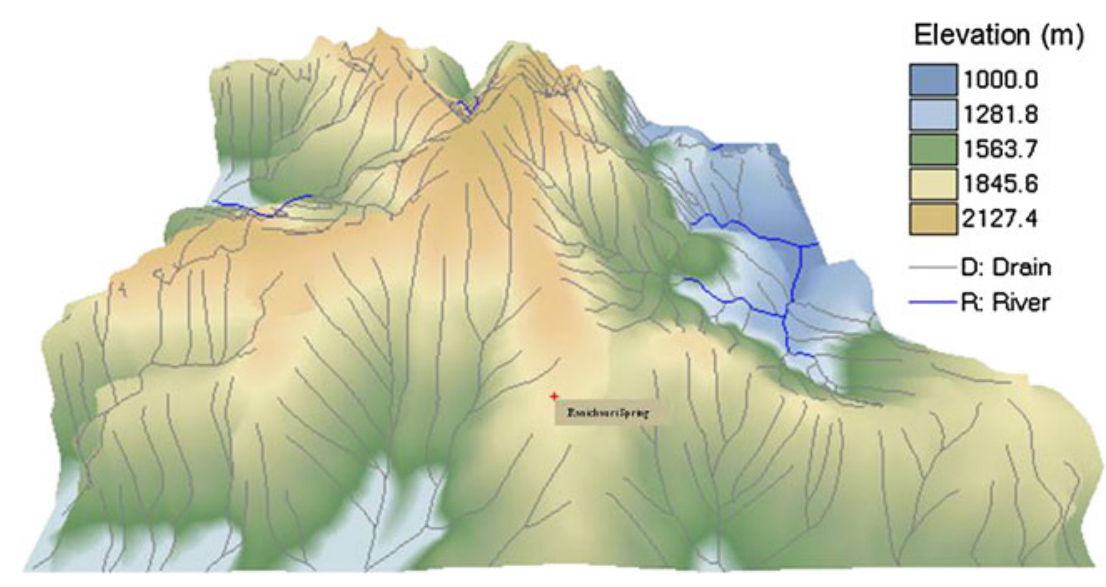

Figure 2. Location map of Ranichauri spring. 


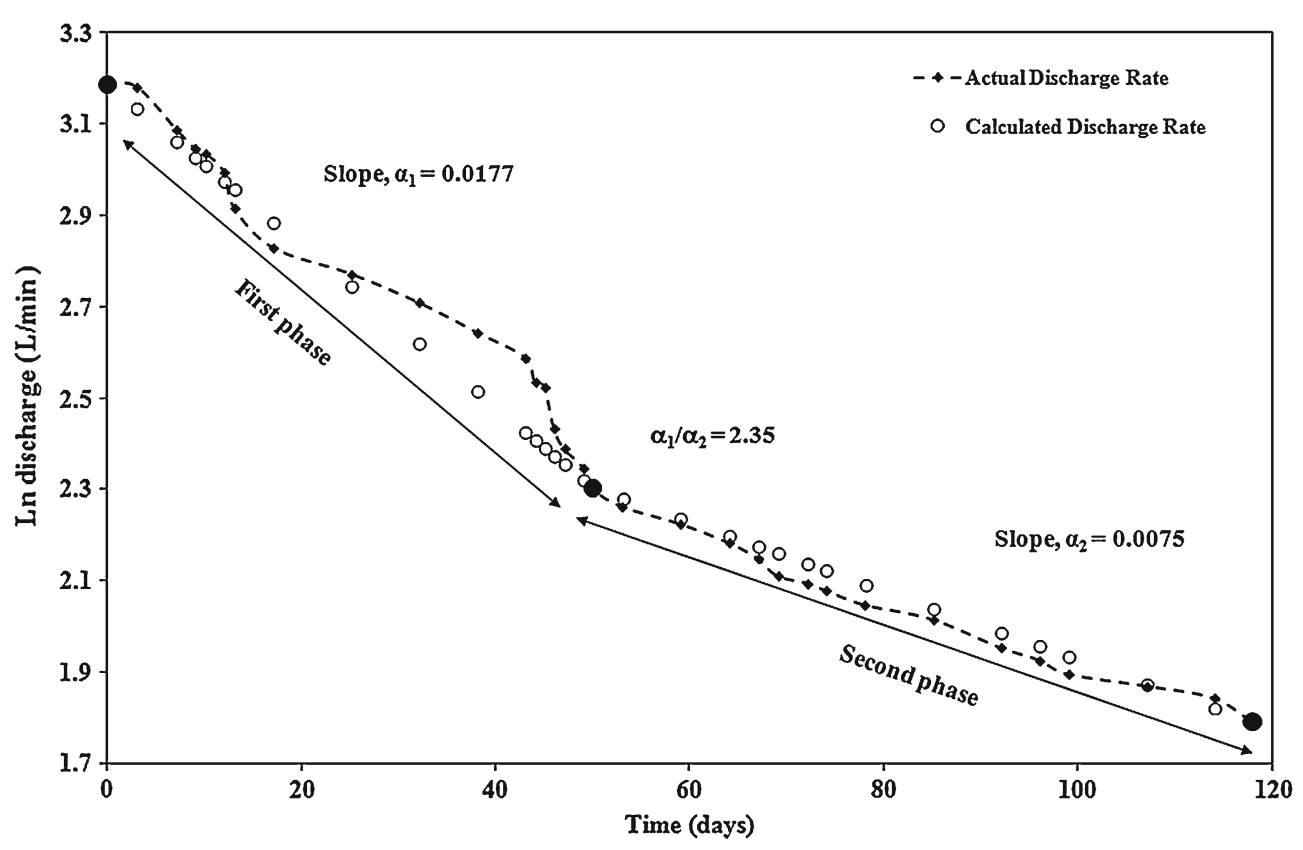

Figure 3. Recession curve for the year 1999.

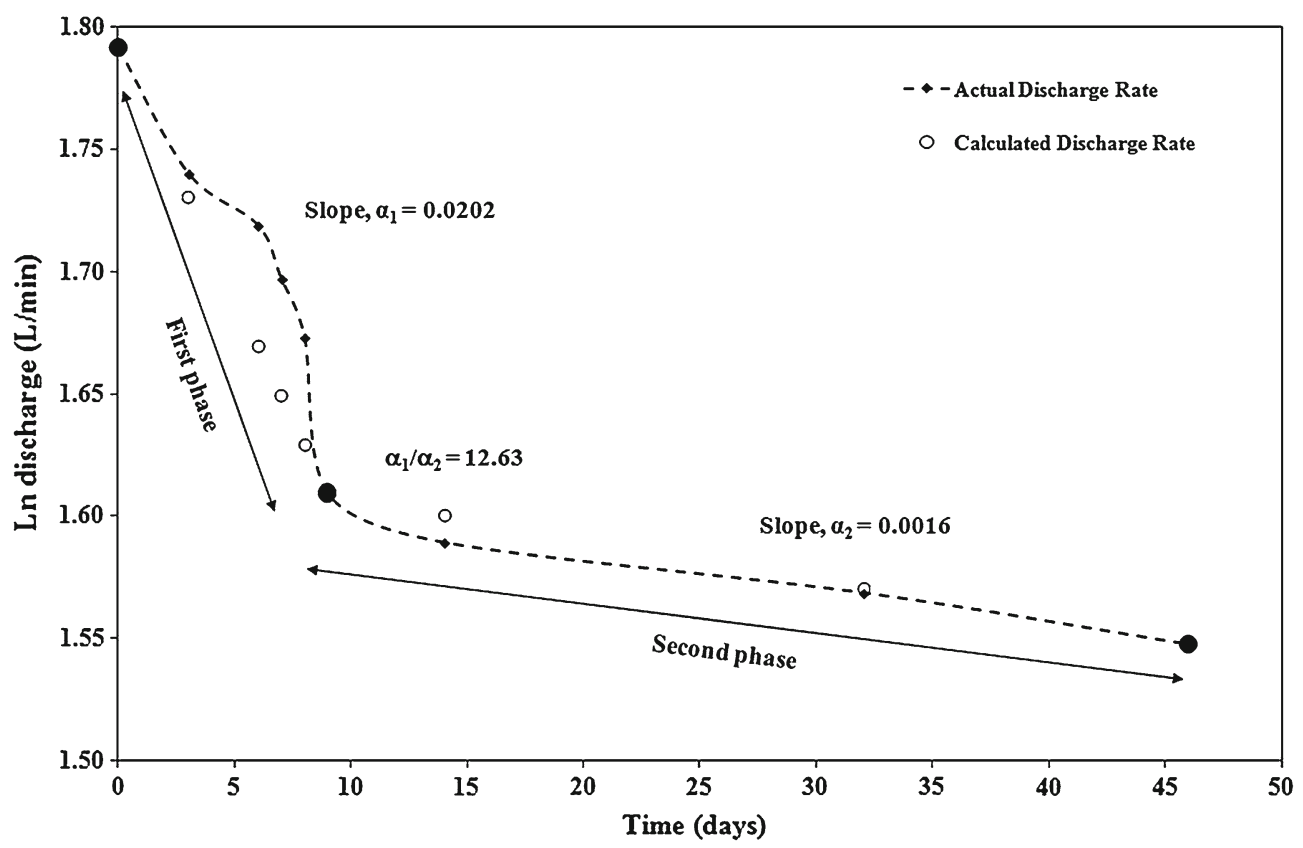

Figure 4. Recession curve for the year 2001. Note that the recession period ends after 46 days and slope-ratio is exceptionally high.

view, spring hydrographs (semi-logarithmic $Q$ vs.t) were developed for eight years and the recession curves are demarcated. Among the all eight curves, only four recession curves for the year's, viz., 1999, 2001, 2002, and 2005 are presented in figures 3-6. Because of their typical behaviour, these curves are specifically chosen. First value of the discharge rate (i.e., the discharge peak) is placed against time $t=0$ and rest of the data is timed consecutively.

\section{Exponential component fitting}

After demarcating the recession curves, next step is to fit these curves with the number of exponential components so that results near accuracy could be achieved. Considering one-dimensional flow through the homogeneous and isotropic spring catchment under a moderate hydraulic head gradient, Boussinesq (1904) fitted the recession curve by 


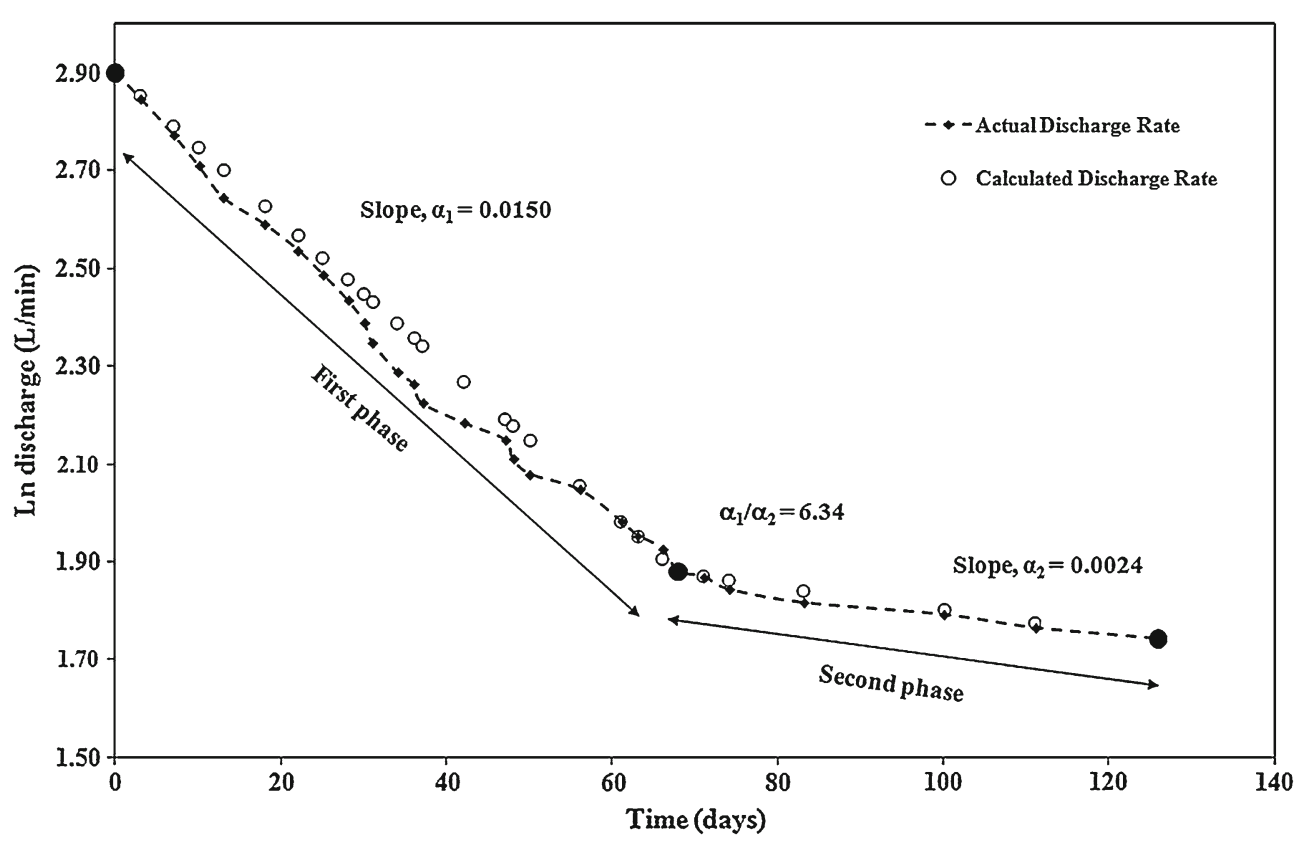

Figure 5. Recession curve for the year 2002.

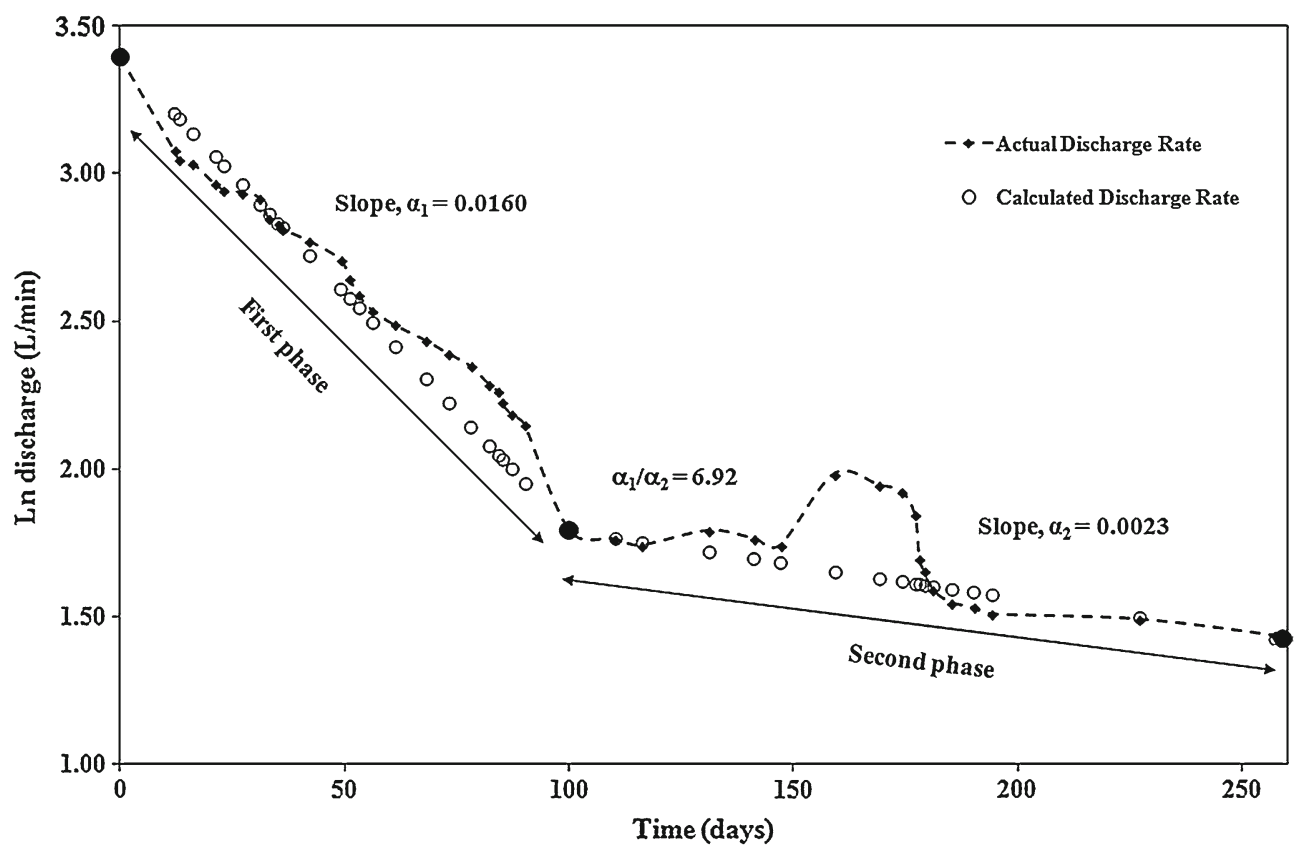

Figure 6. Recession curve for the year 2005. Note the increase in spring discharge in the month of March 2006 due to rainfall in the month of January 2006.

a sum of two exponential components. The original Boussinesq equation describes the flow in unconfined aquifers. Brutsaert and Lopez (1998) have thoroughly discussed the three theoretical solutions of the Boussinesq equation that have the general form of a power function as:

$$
\frac{d Q}{d t}=-a Q^{b}
$$

In equation (1), $Q$ is the recession flow, $t$ is time, and $a, b$ are constant coefficients. The coefficient $a$ can be directly related to the groundwater reservoir's characteristics and $b$ is an exponent whose value depends on the time scale (Malvicini et al. 2005). They analyzed the spring flow data by considering it a linear reservoir to determine the dry season spring flow behaviour and half-life of the spring. A more general analytical expression 
into hydro-technical theory and practice for defining a hydrograph recession curve in a long lasting dry period (with no precipitation) is introduced by Maillet (1905) and that can be written as:

$$
Q_{t}=Q_{0} e^{-\alpha t}
$$

In equation (2), $Q_{t}$ is the discharge at time $t, Q_{0}$ is the discharge rate at the start of the recession, and $\alpha$ is a recession coefficient which depends upon the geological and morphological structure of the catchment analyzed.

Alternatively, Mangin (1975) proposed the recession curve fitting into non-exponential component for earlier duration and an exponential component for later duration. Amit et al. (2002) supported the Boussinesq results and showed that the recession curves can be well fitted by a function that consists of two exponential terms. However, unless the recession curve decay is very smooth, the number of exponential components required to fit a recession curve depends on the number-of-time it changes slope. Petras (1986) reported that a change in the slope of the recession curve can be attributed to the heterogeneity of the spring catchment. Furthermore, a recession curve also changes slope depending on the quantity of recharge the spring catchment received during the accession period. If the time-lag between rainfall and the spring discharge is more, such changes generally appear during the recession period (see figure 6). An unusual rainfall event (i.e., $29 \mathrm{~mm} /$ day) in the month of January 2006 increases the spring discharge in the month of March 2006. Hence, the recession curve changes its general slope pattern for few days and later on adopts the initial trend. While fitting the curves mathematically, such occasional changed slope patterns are not considered for writing a new exponential component. Only when the recession curve is presenting the changing slope pattern for considerable duration every year, a new exponential component is fitted. The changes in recessioncurve slopes can be easily interpreted visually from the recession graph before fitting. Due to the site specific nature, all spring catchments have their unique features (especially, from geological point of view). Hence, the number of exponential components required to fit a recession curve for a particular spring may vary. For that reason, before evaluating the spring parameters, it is necessary to compare the results by fitting the recession curve with one, two, and three exponential components. For the purpose, analytical expressions defining the spring-hydrograph's recession curve and its yield for the recession period are required. A modified form of equation (2) that represents the recession curve with $N$ number of exponential components can be written as:

$$
Q_{t_{i}}=Q_{0_{i}} \cdot e^{-\alpha_{i} t_{i}} ; \quad \text { for } i=1 \text { to } N, t_{i}=0 \text { to } T_{i}
$$

In equation (3), $Q_{0_{i}}$ and $Q_{t_{i}}$ represent the discharge-rates of the $i$ th component of the recession curve at the initial and at time $t_{i}$, respectively; $T_{i}$ is the total number of days in the particular exponential component; and $\alpha_{i}$ is the slope of the $i$ th exponential component of the recession curve on the logarithmic scale and is termed as exponential coefficient (or occasionally depletion coefficient). Based on equation (3), a general equation for computing spring yield $V$ for the recession period with one exponential component can be expressed as:

$$
V=\sum_{t_{1}=0}^{T_{1}} Q_{t_{1}}=\sum_{t_{1}=0}^{T_{1}} Q_{0_{1}} \cdot e^{-\alpha_{1} \cdot\left(t_{1}-0\right)} .
$$

\begin{tabular}{|c|c|c|c|c|c|c|}
\hline \multirow{2}{*}{$\begin{array}{l}\text { Year } 1999 \\
\text { Slope }\end{array}$} & \multirow{2}{*}{$\begin{array}{c}\begin{array}{c}\text { One-exponential } \\
\text { component }\end{array} \\
\alpha_{1}=0.0118\end{array}$} & \multicolumn{2}{|c|}{$\begin{array}{c}\text { Two-exponential } \\
\text { components }\end{array}$} & \multicolumn{3}{|c|}{$\begin{array}{l}\text { Three-exponential } \\
\text { components }\end{array}$} \\
\hline & & $\alpha_{1}=0.0177$ & $\alpha_{2}=0.0075$ & $\alpha_{1}=0.0139$ & $\alpha_{2}=0.0411$ & $\alpha_{3}=0.0075$ \\
\hline $\begin{array}{l}\text { Initial discharge } \\
\text { rate }(\mathrm{L} / \mathrm{min})\end{array}$ & 24.19 & 24.19 & 10.00 & 24.19 & 13.33 & 10.00 \\
\hline Duration (days) & 118 & 50 & 68 & 43 & 7 & 68 \\
\hline $\begin{array}{l}\text { Calculated discharge } \\
\text { (million-litres) }\end{array}$ & 2.22 & -1 & 9 & & -2.01 & \\
\hline $\begin{array}{l}\text { Actual discharge } \\
\text { (million-litres) }\end{array}$ & & & $-1.98-$ & & & \\
\hline $\begin{array}{l}\text { Over }(+) / \text { under }(-) \\
\text { prediction from } \\
\text { actual }(\%)\end{array}$ & +12.00 & $\longrightarrow+$ & $77 \longrightarrow$ & & $-+1.66-$ & \\
\hline
\end{tabular}

Table 1. Comparison of discharge calculated by fitting recession curve for the year 1999 by one, two, and threeexponential components. 
Similarly, the spring yield $V$ for the recession period with $N$ number of exponential components can be obtained by modifying equation (4) as:

$$
\begin{aligned}
V= & {\left.\left[\sum_{t_{i}=T_{i-1}}^{T_{i}-1} Q_{0_{i}} \cdot e^{-\alpha_{i} \cdot\left(t_{i}-T_{i-1}\right)}\right]\right|_{\text {for } i=1 \text { to } N-1} } \\
& +\left.\left[\sum_{t_{N}=T_{N-1}}^{T_{N}} Q_{0_{N}} \cdot e^{-\alpha_{N} \cdot\left(t_{N}-T_{N-1}\right)}\right]\right|_{\text {for } i=N} .
\end{aligned}
$$

As it is already mentioned in section 3 that first value of the recession period is kept against time equal to zero; therefore, in equation (5), $T_{0}$ will also be equal to zero. To avoid any confusion to the readers, all the parameters of equations (35) are kept same as found in literature. Using the analytical equation (3), the recession curve of the year 1999 is fitted with one, two, and threeexponential components. The evaluated exponential coefficients (i.e., slopes) for the three cases are presented in table 1 . From the slope, initial discharge and duration values of various exponential components, three independent expressions based on equations (4) and (5) for calculating spring yield in a recession period of 118 days can be written as: For one-exponential component:

$$
V=\sum_{t_{1}=0}^{118} Q_{t_{1}}=\sum_{t_{1}=0}^{118} 24.19 \times e^{-0.0118 \times\left(t_{1}-0\right)} .
$$

For two-exponential components:

$$
\begin{aligned}
V & =\left.\left[\sum_{t_{1}=T_{0}=0}^{50-1} 24.19 \times e^{-0.0177 \times\left(t_{1}-0\right)}\right]\right|_{\text {for } i=1 \text { to } 1} \\
& +\left.\left[\sum_{t_{2}=50}^{118} 10.00 \times e^{-0.0075 \times\left(t_{2}-50\right)}\right]\right|_{\text {for } i=2} \cdot
\end{aligned}
$$

For three-exponential components:

$$
\begin{aligned}
V & =\left[\sum_{t_{1}=T_{0}=0}^{43-1} 24.19 \times e^{-0.0139 \times\left(t_{1}-0\right)}\right. \\
& \left.+\sum_{t_{2}=43}^{50-1} 13.33 \times e^{-0.0411 \times\left(t_{2}-43\right)}\right]\left.\right|_{\text {for } i=1 \text { to } 2} \\
& +\left.\left[\sum_{t_{3}=50}^{118} 10.00 \times e^{-0.0075 \times\left(t_{3}-50\right)}\right]\right|_{\text {for } i=3}
\end{aligned}
$$

Calculated spring yield for the recession period with one-, two-, and three-exponential components from equations (6-8) are computed and tabulated in table 1 . Perusal of the table 1 clearly indicates that the fitting of the recession curve by exponential components for all the three cases overpredicts the recession-period discharge of the spring in general; though, the predictions by mathematical expression with two-exponential components is near accuracy (i.e., $+0.77 \%$ ) as compared to one (i.e., $+12 \%)$ and three-exponential component (i.e., $+1.66 \%$ ) results. Hence, the quantitative analysis for the eight-year recession curves will be based on the mathematical expressions fitted with two-exponential components.

\section{Results and discussion}

\subsection{Interpretation of slope values}

Recession curves for the eight years are fitted with two-exponential components following the procedure as described in section 4 . The exponential coefficients (i.e., the slopes $\alpha_{1}$ and $\alpha_{2}$ ) for the two demarcated segments in all the recession curves are presented in table 2 and are also depicted on the selected figures (3-6). The division of recession curve in two segments is demarcated by solid circular markers (i.e., •). Slope-ratios (i.e., $\alpha_{1} / \alpha_{2}$ ) for the eight recession curves are also tabulated in table 2. Except for the years 2001, 2002, and 2005 with the highest for year 2001 (i.e., 12.63), the values of the slope-ratios in general are comparable. Abrupt change in slope of the recession curve leads to such high value (see figure 4). During the first phase of the recession periods in these three years, rapid depletion in the catchment-storage has occurred. Obviously, it is through the specific porous medium of the catchment that has high permeability. It is worth mentioning that a spring catchment in general, is a complex combination of different geological mediums having marked difference in permeability values. Hence, lesser recharging of the spring catchment is the basic cause for this abrupt change in slope. For better understanding of the concept in simpler way, a hypothetically sketched schematic map of the spring catchment is shown in figure 7. Since, the Ranichauri spring under study is giving accurate results with twoexponential components; the hypothetical sketch in figure 7 is shown with two portions having different permeability values separated by a contact layer. Shaded region of the sketch represents the low permeability region. Depending on the head of water in the particular portion, water movement across the contact layer is possible in both ways (as shown by arrows). In the hypothetical sketch, water movement from the portion 2 to portion 1 is shown at particular time $t_{1}$. First phase of recession curves (figures 3-6) represents the contribution of the spring catchment mainly from portion 2. However, it is worth mentioning that the 
Table 2. Slope ratio of recession curves for different years.

\begin{tabular}{|c|c|c|c|c|c|c|c|c|c|}
\hline (1) Year & 1999 & 2000 & 2001 & 2002 & 2003 & 2004 & 2005 & 2006 & Average \\
\hline (2) Rainfall (mm) & 939.70 & 1334.40 & 719.10 & 1254.60 & 1173.80 & 1174.70 & 1386.90 & 897.00 & 1110.03 \\
\hline (3) $Q_{0_{1}}(\mathrm{~L} / \mathrm{min})$ & 24.19 & 30.30 & 6.00 & 18.18 & 18.46 & 20.00 & 29.85 & 20.00 & 20.87 \\
\hline (4) $\alpha_{1}\left(\right.$ day $\left.^{-1}\right)$ & 0.0177 & 0.0123 & 0.0202 & 0.0150 & 0.0133 & 0.0205 & 0.0160 & $0.0206^{+}$ & 0.01695 \\
\hline $\begin{array}{l}\text { (5) Number of days for } \\
\text { which the slope } \\
\alpha_{1} \text { is evaluated }\end{array}$ & 50 & 79 & 9 & 68 & 63 & 25 & 100 & 43 & $\sim 55$ \\
\hline (6) $Q_{0_{2}}(\mathrm{~L} / \mathrm{min})$ & 9.52 & 11.93 & $\$$ & 7.16 & 7.27 & 7.87 & 11.75 & 7.87 & 8.22 \\
\hline (7) $\alpha_{2}\left(\right.$ day $\left.^{-1}\right)$ & 0.0075 & 0.0055 & $0.0016^{@}$ & 0.0024 & 0.0057 & 0.0070 & 0.0023 & 0.0047 & 0.0046 \\
\hline $\begin{array}{l}\text { (8) Number of days for } \\
\text { which the slope } \\
\alpha_{2} \text { is evaluated }\end{array}$ & 68 & 108 & 37 & 58 & 90 & 71 & 159 & 93 & $\sim 86$ \\
\hline $\begin{array}{l}\text { (9) Exponential coefficients } \\
\text { (Slopes) ratio }\left(\alpha_{1} / \alpha_{2}\right)\end{array}$ & 2.35 & 2.21 & $12.63^{\#}$ & $6.34^{\#}$ & 2.34 & 2.92 & $6.92^{\#}$ & 4.37 & 3.69 \\
\hline
\end{tabular}

$\$$ Since, the recession period of the spring was for 46 days (i.e., $9+37$ ) only that is less than 55 days (i.e., average number of days for which the slope of first exponential component is evaluated). Hence, there is no $Q_{2}$ value for this particular case. + It indicates the major contribution to spring discharge from the catchment-portion having highest permeability and is termed as quick-flow.

@ It indicates the major contribution to spring discharge from the catchment-portion having lowest permeability and is termed as base-flow.

\# Slope ratios with exceptionally high values. Due to abrupt change in slope of the recession curve from first exponential component to second leads to such high values.

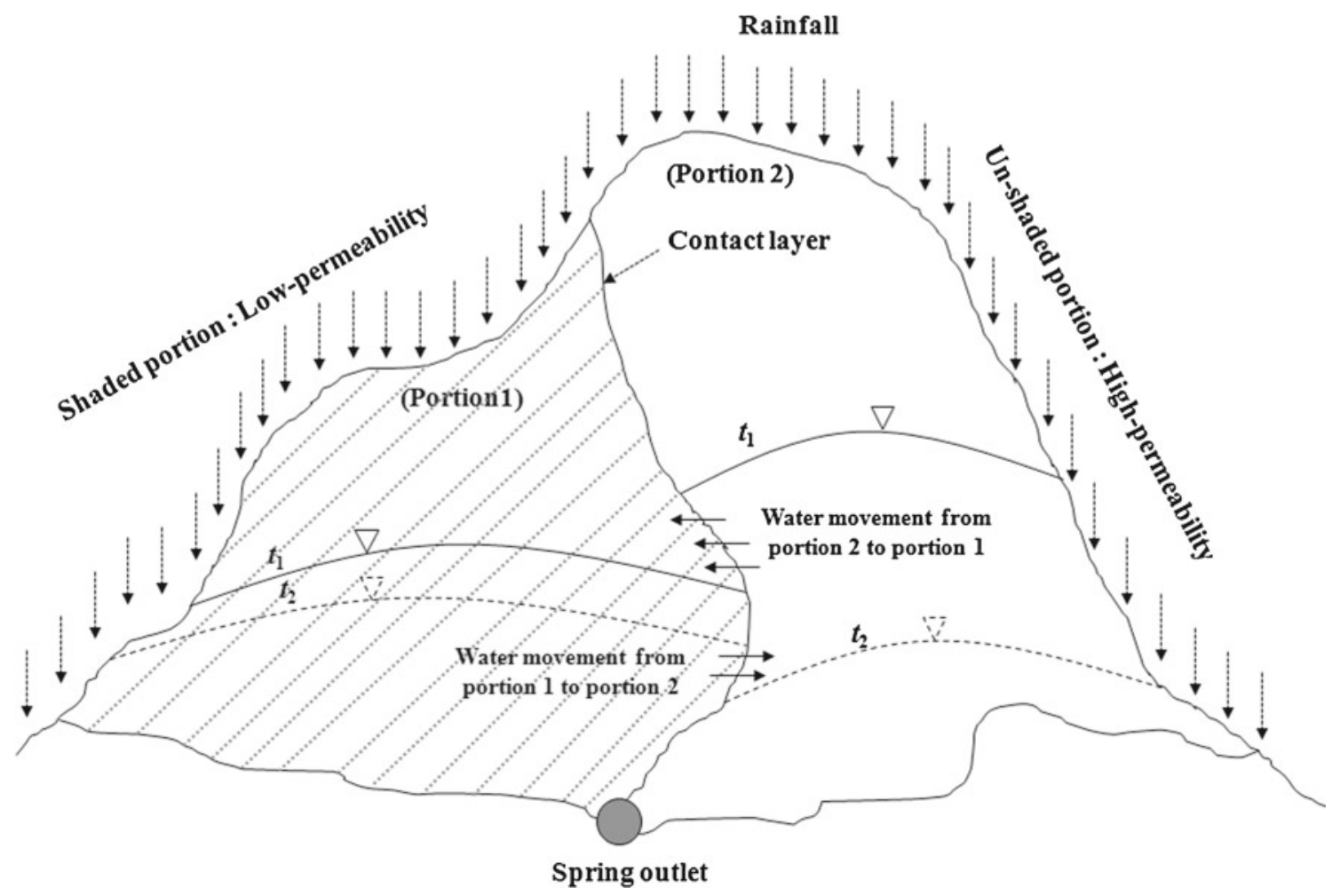

Figure 7. Hypothetically sketched spring catchment showing two portions having different permeability values.

actual spring discharge includes the contribution from both the portions and distinguishing these contributions (to the total discharge-rate) is a very difficult task and needs further study. As soon as the water level (or head) in portion 2 becomes lower than portion 1 (say at time $t_{2}$ ), water will start seeping towards portion 2. From the above discussion, it is clear that the major contribution to spring discharge from portion 2 will steer the recession curve steeply; and if this contribution is 
further increased by drainage from portion 1 , it will flatten the recession curve.

Rainwater after infiltrating through the catchment's surface-soil recharges the two portions of the catchment. The storage-rate (i.e., intake rate) of water in particular portion of the spring catchment depends on its permeability (as is shown in figure 7 by different water levels at time $t_{1}$ ). Volume of water stored in particular portion of the spring depends on its storage capacity. From this justification it is clear that the maximum volume of water in lesser time will be stored in the portion with highest permeability and capacity. Conversely, it is also true that the portion having highest permeability will deplete earlier in comparison to catchmentportions with low permeability (see the water level at time $t_{2}$ ). From the above discussion, it is clear that the 'temporal variation in spring discharge' depends on the capacity and permeability of different spring-portions within the catchment. More elaborately, the permeability of the porous medium is responsible for the discharge rate and its capacity is responsible for perennial or seasonal behaviour of the spring.

The year 2001 received $719.10 \mathrm{~mm}$ of rainfall and that was exceptionally lower than the average annual of the region (i.e., $1110.03 \mathrm{~mm}$ ). Moreover, the major distribution of this rainfall was concentrated in the second half of the monsoon season. Unfortunately, the rainfall intensity was not monitored. However, the rainfall's major concentration in the second half of the monsoon-season strengthens the possibility that the initial moisture content of the surface-soil was high. The mentioned factor was probably responsible for lesser recharging of all portions of the catchment and that was reflected clearly by the spring hydrograph. Steep slope of the recession curve in the first phase of the recession period clearly shows that the spring discharge-rate was dependent on the high permeability portion of the spring catchment (i.e., portion 2) and that was depleted within a period of 9 days only. Conversely, the mild slope of recession curve in the second phase of recession period reflects the dependency of spring discharge-rate on the low permeability portions of the catchment (i.e., portion 1).

In spite of rainfall sufficiency in years 2002 and 2005 (i.e., 1254.60 and $1386.90 \mathrm{~mm}$, respectively), the basic cause for high slope-ratios in these two years is again same (i.e., lesser recharging of the spring catchment). However, the basis of lesser recharging is different for these cases. It can probably be attributed to the lesser infiltration opportunity time, the rain-water got due to high rainfall-intensity than the infiltration rate of catchment-soil. Consequent to this fact, major component of rain water gets converted into overland flow and escaped from the catchment.
The slope values marked with '@' and ' + ' in table 2 are the two extremes of the recession curves for the eight-year data analyses. Maximum value (i.e., 0.0206) of exponential coefficient (i.e., slope) indicates the major contribution to drainage from the catchment-portion having highest permeability and can suitably be termed as quick-flow. In other terms, we can express that it represents the least recharging of the spring catchment's lesser permeable portion whose contribution flattens the recession curve. Note that the rainfall reception in year 2006 is $~ 19 \%$ less than the average. Amit et al. (2002) in a study reported that the quickflow represents the drainage through local cracks and is a consequence of geometry of local fractures and their connectivity. However, they have not mentioned about the contribution from the lesser permeable portions of the catchment during quick flow. On the other hand, the minimum value (i.e., 0.0016) indicates the major contribution to drainage from the catchment portion having lowest permeability and is usually termed as base-flow.

\subsection{Formulation of the master discharge function for the recession period}

The mean values of all the parameters of the fitted exponential components are presented in the last column of table 2 . Using the mean values of rows $(4,5,7$ and 8$)$, the master discharge function of the spring for the recession period can conveniently be formulated as:

$$
\begin{aligned}
V= & \sum_{t_{1}=0}^{55-1} Q_{0_{1}} \times e^{-0.01695 \times\left(t_{1}-0\right)} \\
& +\sum_{t_{2}=55}^{151} Q_{0_{2}}\left(=Q_{55}\right) \times e^{-0.0046 \times\left(t_{2}-55\right)} .
\end{aligned}
$$

In equation (9), $Q_{0_{1}}$ is the initial discharge-rate for first phase of the recession period with an average duration of 55 days; $Q_{0_{2}}$ is the initial discharge-rate for second phase of the recession period and is equal to the discharge rate of the spring after 55 days in first phase. It means that the last discharge-rate value of first-phase recession period will be the initial discharge-rate for the second phase. Although, the mean duration for evaluating slope $\alpha_{2}$ in second phase of the recession period came equal to 86 days, for the purpose of testing the formulated master discharge-function's performance, the actual durations are considered for the second-phase recession period. It is for the reason that the different duration recession-periods were witnessed during the data collection years.

For evaluating the performance of the formulated master discharge function of the spring for 
Table 3. Comparison of the calculated discharge evaluated using developed discharge-function with the actually monitored results.

\begin{tabular}{lccccccccc}
\hline Year & 1999 & 2000 & 2001 & 2002 & 2003 & 2004 & 2005 & 2006 & Average \\
\hline $\begin{array}{l}\text { Calculated discharge of } \\
\text { the spring (million-litres) }\end{array}$ & 2.02 & 3.29 & 0.28 & 1.58 & 1.79 & 1.47 & 3.80 & 1.82 & 1.94 \\
$\begin{array}{l}\text { Actual discharge of } \\
\text { the spring (million-litres) }\end{array}$ & 1.98 & 3.60 & 0.34 & 1.59 & 2.00 & 1.56 & 3.48 & 1.69 & 2.03 \\
$\begin{array}{l}\text { Percentage error in } \\
\text { calculating discharge over actual }\end{array}$ & +2.00 & -8.76 & -16.46 & -0.80 & -10.31 & -5.51 & +9.19 & +7.67 & -4.66 \\
$\begin{array}{l}\text { Efficiency of the spring } \\
\text { discharge-function, } E\end{array}$ & & & & & & & & & \\
\end{tabular}

the recession period, the actually monitored $Q_{0_{1}}$ (row 3, table 2) and the second-phase recessionperiod durations (row 8, table 2) are incorporated in equation (9) and the calculated-discharge of the spring for all the eight years is tabulated in table 3 . The over- and under-calculated errors from the actually monitored discharge are also presented in the table. The calculated results are comparable with the actual spring yield except for the year 2001. It is already explained in section 5.1 that the monsoon rainfall in year 2001 was significantly below average. However, the winter season of the year 2001-2002 received good amount of rainfall ( $\sim 507 \mathrm{~mm})$ starting from the mid-December 2001 to end-March 2002. This unusual rainfall increases the spring discharge that break-off the recession period only after 46 days from the discharge peak (see figure 4). Since, this recession period was even smaller than the average annual-duration of the first exponential component (i.e., 55 days) of the spring, the predicted results notably varied from the actual.

\subsection{Efficiency of the formulated master discharge function for the recession period}

The process of assessing the performance of a hydrologic model requires the hydrologist to make subjective and/or objective estimates of the 'closeness' of the simulated behaviour of the model to the field observations (Krause et al. 2005). Alternatively, the efficiency criterion is defined as mathematical measures of how well a formulated-model simulation fits the available observations (Beven 2001). In the present study, the Nash-Sutcliffe efficiency criterion has been used to test the performance of the formulated master dischargefunction (equation 9) of the spring for the recession period. In mathematical terms, the criterion can be written as:

$$
E=1-\frac{\sum_{i=1}^{n}\left(O_{i}-P_{i}\right)^{2}}{\sum_{i=1}^{n}\left(O_{i}-\bar{O}\right)^{2}}
$$

In equation (10), $E$ is the efficiency; $O_{i}$ is the observed and $P_{i}$ is the predicted value. The symbol $\bar{O}$ represents the average of the observed values. The range of $E$ lies between 1.00 (perfect fit) and $-\infty$. Incorporating the observed and predicted values of spring discharge from table 3 in equation (10), the efficiency $E$ value comes equal to 0.965 .

\section{Summary and conclusions}

Prediction of spring discharge-rate is the key to the proper management of water in the recession period. The behaviour of a spring can be administrated and forecasted by studying its hydrograph. In the present study, therefore, an effort has been made to formulate the master discharge function for computing the spring flow for the recession period based on the present day discharge-rate. For the purpose, eight-year temporal discharge data of Ranichauri spring was procured from the AICRP on Groundwater Utilization, Department of Irrigation and Drainage Engineering, G B Pant University of Agriculture and Technology, Pantnagar, Uttarakhand, India. The analyses have been completed after fitting the eight-year recession curves by exponential components. The following conclusions have been drawn from the results:

- It is concluded that the fitting of the recession curves by two-exponential components predicts the spring discharge in the recession period near accuracy (i.e., with error $+0.77 \%$ ) as compared to one- (i.e., with error $+12.00 \%$ ) and three-exponential components (i.e., with error $+1.66 \%$ ) results.

- The values of the slope-ratios $\left(\alpha_{1} / \alpha_{2}\right)$ are comparable except for the years 2001, 2002, and 2005 with the highest value in the year 2001 (i.e., 12.63). Abrupt change in slope of the recession curve leads to such high value. Lesser recharging of the different portions of the spring catchment (especially having low permeabilities) is the basic 
reason for the exceptionally high slope-ratios. Further, the conclusion is drawn that the 'temporal variation in spring discharge' depends on the capacity and permeability of different springportions within the catchment. The permeability of the porous medium is responsible for the discharge rate and its capacity is responsible for perennial or seasonal behaviour of the spring.

- The maximum value of slope (i.e., 0.0206 in year 2006) indicates the major contribution to spring discharge from the catchment-portion having highest permeability and can be termed as quickflow. On the contrary, the minimum value (i.e., 0.0016 in year 2001) indicates the major contribution to spring discharge from the catchment portion having lowest permeability in comparison to high permeable portion and is usually termed as base-flow.

- Based on the average values of evaluated parameters for eight years' recession curves, master discharge-function of the spring for the recession period is formulated with two exponential components. The formulated discharge-function predicted the spring discharge in well agreement with the actually monitored data except for the year 2001. It is because of the fact that the recession period for the said year was only for 46 days and that is even lesser than the fitted average annual-duration of the first exponential component (i.e., 55 days) of the spring.

- The Nash-Sutcliffe efficiency $E$ of the formulated master discharge-function of the spring for the recession period comes equal to 0.965 .

\section{Acknowledgements}

The authors would like to thank All India Coordinated Research Project on Groundwater Utilization, Department of Irrigation and Drainage Engineering, G B Pant University of Agriculture and Technology, Pantnagar, Uttarakhand, India for providing the relevant data for completing the study. In addition, the authors are also grateful to the anonymous reviewers for their efforts to improve this manuscript.

\section{References}

Agarwal A, Bhatnaga N K, Nema R K and Agrawal N K 2012 Rainfall dependence of springs in the Midwestern Himalayan hills of Uttarakhand; Mt. Res. Dev. 32(4) 446-455.
Amit H, Lyakhovsky V, Katz A, Starinsky A and Burg A 2002 Interpretation of spring recession curves; Ground Water 40(5) 543-551.

Beniston M 2003 Climatic change in mountain regions: A review of possible impacts; Clim. Change 59 5-31.

Beven J K 2001 Rainfall-Runoff Modelling - The Primer; John Wiley \& Sons Ltd., Chichester, 319p.

Boussinesq J 1904 Recherches theoretique sur l'ecoulement des nappes d'eau infiltrees dans le sol et sur le debit des sources; J. Math. Pures et Applignées 10(1) 5-78.

Brutsaert W and Lopez J P 1998 Basin-scale geohydrologic drought flow features of riparian aquifers in the southern Great Plains; Water Resour. Res. 34(2) 233-240.

Cruz R V, Harasawa H, Lal M, Wu S, Anokhin Y, Punsalmaa B, Honda Y, Jafari M, Li C and Huu Ninh N 2007, Asia; In: Climate Change 2007: Impacts, Adaptation and Vulnerability (eds) Parry M L, Canziani O, Palutikof J P, van der Linden P J and Hanson C, Contribution of Working Group II to the Fourth Assessment Report of the Intergovernmental Panel on Climate Change, Cambridge Univ. Press, Cambridge, U.K., pp. 469-506.

IPCC 2007 Climate change 200\%: Climate change impacts, adaptation and vulnerability, Working Group II contribution to the Intergovernmental Panel on Climate Change Fourth Assessment Report, Summary for policymakers, 23p.

Krause P, Boyle D P and Base F 2005 Comparison of different efficiency criteria for hydrological model assessment; Adv. Geosci. 5 89-97.

Maillet E 1905 Essais d'Hydraulique Souterraine et Fluviale; Herman, Paris, France.

Malvicini C F, Steenhuis T S, Walter M T, Parlange J-Y and Walter M F 2005 Evaluation of spring flow in the uplands of Matalom, Leyte, Philippines; Adv. Water Resour. 28(10) 1083-1090.

Mangin A 1975 Contribution a l'étude hydrodinamique des aquif'eres karstiques; Ann. Spéléologie 29 285-382, 495-601 and 30 21-124.

Petras I 1986 An approach to the mathematical expression of recession curves; Water S. Afr. 12(3) 145-150.

Qiu J 2008 The third pole; Nature 454 393-396.

Rees G H and Collins D N 2006 Regional differences in response of flow in glacier-fed Himalayan rivers to climate warming; Hydrol. Process. 20 2157-2167.

Singh P, Kumar V, Thomas T and Arora M 2008 Changes in rainfall and relative humidity in river basins in northwest and central India; Hydrol. Process. 22 2982-2992.

Tallaksen L M 1995 A review of baseflow recession analysis; J. Hydrol. 165 349-370.

Tambe S, Arrawatia M L, Bhutia N T and Swaroop B 2011 Rapid, cost effective and high resolution assessment of climate-related vulnerability of rural communities of Sikkim Himalaya, India; Curr. Sci. 101(2) 165-173.

Xu J C 2008 The highlands: A shared water tower in a changing climate and changing Asia, Working paper no. 64, World Agrofor. Cent. Nairobi.

Xu J C, Grumbine R E, Shrestha A, Eriksson M, Yang X, Wang Y and Wilkes A 2009 The melting Himalayas: Cascading effects of climate change on water, biodiversity, and livelihoods; Conserv. Biol. 23(3) 520-530.

Xu Z X, Chen Y N and Li J Y 2004 Impact of climate change on water resources in the Tarim River basin; Water Resour. Manag. 18 439-458. 